\title{
Continuing the search for mutational drivers in esophageal adenocarcinoma
}

\author{
Pamela Samson, MD, MPHS
}

\footnotetext{
From the Department of Radiation Oncology, Washington University in St Louis School of Medicine, St Louis, Mo.

Disclosures: Author has nothing to disclose with regard to commercial support.

Received for publication Dec 4, 2017; accepted for publication Dec 18, 2017; available ahead of print Feb 8, 2018. Address for reprints: Pamela Samson, MD, MPHS, Department of Radiation Oncology, Washington University in

St Louis School of Medicine, 4511 Forest Park Ave, CB 8224, St Louis, MO 63108 (E-mail: psamson@wustl. edu).

J Thorac Cardiovasc Surg 2018;155:1900-1

$0022-5223 / \$ 36.00$

Copyright $\subset 2018$ Published by Elsevier Inc. on behalf of The American Association for Thoracic Surgery https://doi.org/10.1016/j.jtcvs.2017.12.076
}

In this issue of the Journal, Whitsett and colleauges ${ }^{1}$ characterize the absence of liver kinase B1 (LKB1, or serine/threonine kinase 11, STK11) in esophageal adenocarcinoma. Previous work has identified LKB1 as a tumor suppressor gene that plays a key role in cell polarity and has downstream effects on AMPK-related kinases to decrease growth and proliferation in nutrient-poor environments. $^{2}$ Initially discovered as the causative mutation in Peutz-Jeghers syndrome, attention has turned to its mutational prevalence in sporadic cancers. ${ }^{3}$ Currently, LKB1 mutations have been documented in up to $30 \%$ of sporadic lung adenocarcinomas and $20 \%$ of cervical cancers, and its loss has been associated with increasing tumor grade and invasiveness. ${ }^{4,5}$

The authors have performed a multifaceted study characterizing LKB1 expression in esophagectomy specimens from their institution (among patients who did not receive induction therapy) and validate their findings among the publicly available esophageal gene expression datasets within The Cancer Genome Atlas and ONCOMINE. In this analysis, Whitsett and colleagues ${ }^{1}$ found low or no expression of LKB1 among their gastroesophageal cancer specimens, with retained expression in the surrounding nonmalignant stroma. RNA silencing was then used to suppress LKB1 expression in a human esophageal cell line, which decreased both LKB1 and downstream AMPK protein expression, resulting in enhanced cell growth compared with controls. Using The Cancer Genome Atlas sequencing data, the authors found that the majority of esophageal cancer specimens harbored shallow (likely heterogenous) deletions of $\mathrm{LKB} 1$, resulting in decreased LKB1 mRNA and protein expression and decreased phospho-AMPK expression. This was further confirmed in the ONCOMINE database, with decreased LKB1 mRNA expression in cancer samples compared with normal esophageal tissue and Barrett's esophagus samples.

Analyses such as these are critical for finding new footholds to identify and refine prognostic factors for esophageal cancer and for developing novel therapeutic

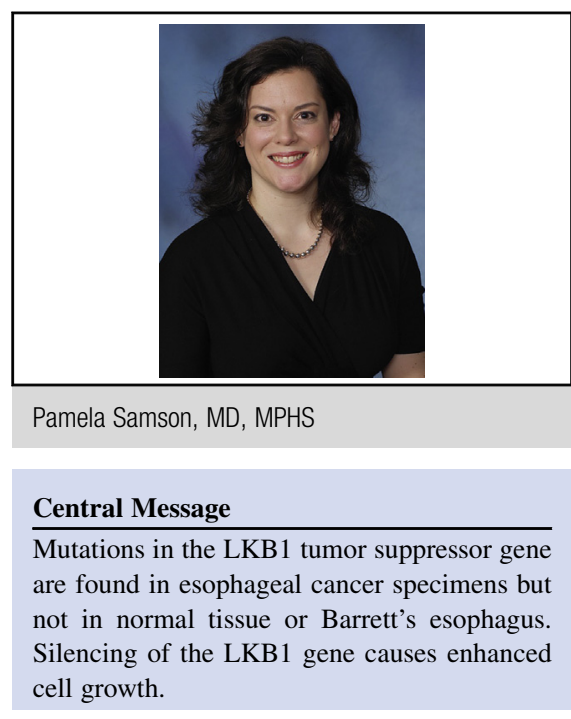

See Article page 1891. strategies. Esophageal adenocarcinoma is known to develop through a clinical sequence of metaplasia and dysplasia that could make inactivating mutations in LKB1 important in characterizing the final steps of progression. This could hold value for the population of patients that receives close endoscopic surveillance for Barrett's esophagus. However, understanding the prognostic role of LKB1 tumor suppressor mutations is limited at this time. Although Whitsett and colleagues ${ }^{1}$ report no survival difference among esophageal adenocarcinoma by LKB1 mutational status, it is important to note that long-term follow-up data may be missing in these large databases, with no cancer-specific mortality information.

Like all malignancies, esophageal cancer is increasingly examined through the lens of actionable targets. As phase II and III trials for immunologic agents in esophageal cancer continue to increase in number, it may seem that inactivating/loss of function mutations might not hold the same exciting therapeutic potential as gain-of-function proto-oncogene mutations that generate tumor-associated antigens. However, LKB1's role in cell metabolism may provide opportunities to act on substrates that would be increased in this unique cellular environment of dysregulation and deserves further attention. ${ }^{6}$ Future directions will also include analyzing expression according to clinical stage and tumor grade, as well as following long-term cancer-specific outcomes for patients with this mutation. 
Dr Pippa Cosper, MD, PhD, Washington University in St Louis, is acknowledged for comments on this editorial.

\section{References}

1. Whitsett TG, Mittal SK, Eschbacher JM, Carson VM, Smith MA, Bremner RM, Inge LJ. LKB1 inactivation occurs in a subset of esophageal adenocarcinomas and is sufficient to drive tumor cell proliferation. J Thorac Cardiovasc Surg. 2018;155:1891-9.

2. Vaahtomeri K, Makela TP. Molecular mechanisms of tumor suppression by LKB1. FEBS Lett. 2011;585:944-51.
3. Hemminki A, Markie D, Tomlinson I, Avizienyte E, Roth S, Loukola A, et al. A serine/threonine kinase gene defective in Peutz-Jeghers syndrome. Nature. 1998; 391:184-7.

4. Contreras CM, Gurumurthy S, Haynie JM, Shirley LJ, Akbay EA, Wingo SN, et al Loss of Lkb1 provokes highly invasive endometrial adenocarcinomas. Cancer Res. 2008:68:759-66.

5. Ji H, Ramsey MR, Hayes DN, Fan C, McNamara K, Kozlowski P, et al. LKB1 modulates lung cancer differentiation and metastasis. Nature. 2007;448:807-10.

6. Momcilovic M, Shackelford DB. Targeting LKB1 in cancer-exposing and exploiting vulnerabilities. Br J Cancer. 2015;113:574-84. 